\title{
The IgE response to Ascaris molecular components is associated with clinical indicators of asthma severity
}

\author{
Emiro Buendía', Josefina Zakzuk ${ }^{1,2}$, Dilia Mercado ${ }^{1}$, Alvaro Alvarez ${ }^{3}$ and Luis Caraballo ${ }^{1,2^{*}}$
}

\begin{abstract}
Background: Asthma is a common chronic disease worldwide and Ascaris lumbricoides infection (ascariasis) is frequent in tropical regions. However, the effect of ascariasis on asthma severity has not been sufficiently explored. We sought to evaluate the influence of the lgE immune response to Ascaris extract and purified house dust mites (HDM) and Ascaris allergens on indicators of asthma severity in patients living in the tropics.

Methods: Asthmatic patients from Cartagena, Colombia were recruited. Clinical assessment included questionnaires, physical examination, allergy skin tests, spirometry, parasite stool examination and lgE antibody measurements. Asthma was diagnosed by a physician according to validated criteria. Indicators of severity were occurrence of severe dyspnea episodes, night awakenings events, $>4$ emergency room (ER) visits and hospitalizations during the last year. Specific IgE to Der p 2, Ascaris spp., Blomia tropicalis and Dermatophagoides pteronyssinus extracts was determined by ImmunoCap. IgE to tropomyosins (Asc I 3, Blo t 10 and Der p 10), Blo t 5 and Asc $s 1$ was detected by ELISA. Logistic regression analyses were used to explore the relationships between sensitization and indicators of asthma severity.

Results: After adjustment for HDM sensitization, Ascaris sensitization remained associated with severe dyspnea (aOR: 1.90, 95\% Cl: $1.08-3.34, p=0.03$ ) and > 4 ER visits (aOR: 2.23, 95\% Cl: $1.15-4.30, p=0.02$ ). We also found that sensitization to the species specific markers Blo t 5 and Asc $s$ 1, as well as the cross-reactive tropomyosins of D. pteronyssinus and Ascaris were associated with $>4$ ER visits. Der $\mathrm{p} 2$ sensitization was associated with bronchodilator responsiveness (aOR: 2.24: 1.25-4.02, $\mathrm{p}=0.01$ ). Remarkably, significantly higher lgE levels to HDM species specific allergens were found in Ascaris sensitized patients.

Conclusions: In this tropical population, IgE sensitization to Ascaris and the cross-reactive tropomyosins was frequent and associated with clinical indicators of asthma severity. The significant relationship between sensitization to the nematode-specific marker Asc s 1 and ER attendance supports these findings. Moreover, ascariasis increases the human IgE responses to HDM specific allergens.
\end{abstract}

Keywords: Asthma severity, Ascaris, House dust mites, lgE, The tropics, Lung function, Atopy, Blomia tropicalis, Dermatophagoides pteronyssinus, Ascariasis, Poverty, Urban

\footnotetext{
* Correspondence: Icaraballog@unicartagena.edu.co

${ }^{1}$ Institute for Immunological Research, University of Cartagena, Cartagena,

Colombia

${ }^{2}$ Foundation for the Development of Medical and Biological Sciences

(Fundemeb), Cartagena, Colombia

Full list of author information is available at the end of the article
}

\section{Biomed Central}

(c) 2015 Buendía et al.; licensee BioMed Central. This is an Open Access article distributed under the terms of the Creative Commons Attribution License (http://creativecommons.org/licenses/by/4.0), which permits unrestricted use, distribution, and reproduction in any medium, provided the original work is properly credited. The Creative Commons Public Domain Dedication waiver (http://creativecommons.org/publicdomain/zero/1.0/) applies to the data made available in this article, unless otherwise stated. 


\section{Background}

Asthma is a common chronic respiratory disease globally distributed, including urban areas of low to middle income countries [1]. The majority of asthma cases are associated with atopy, but clinical presentation may vary under the influence of other risk factors. For example, the severity of symptoms could be influenced by optimal medication prescription, adherence to therapy, environmental exposures and genetic factors.

In the Tropics asthma cases are strongly associated with sensitization to house dust mites (HDM) such as Blomia tropicalis and Dermatophagoides pteronyssinus, which are the most important risk factors for this disease, probably as a result of the permanent exposure to these allergen sources. In addition, ascariasis, caused by the nematode Ascaris lumbricoides, is also frequent and several outcomes resulting from the coexistence of these problems have been reported, suggesting an important influence of this infection on the pathogenesis, prevalence, diagnosis and treatment of asthma [2,3].

Ascariasis is the most frequent soil-transmitted helminthiasis [4,5]. In South American countries it is more common in rural [6-9] than urban settings [10,11]. Its influence on asthma is still controversial; population surveys in lightly-infected urban communities have shown that the infection is a predisposing factor for allergen sensitization [12,13] and asthma symptoms [14-16], while studies in heavily-infected rural populations have found that ascariasis may protect from some allergic symptoms $[17,18]$. Therefore, more research is needed to understand the relationship between helminth infections and allergy, particularly to explore the potential HDM-independent effect of ascariasis on the presence and severity of allergy symptoms.

Active ascariasis may exacerbate asthma symptoms [10], in some patients as a consequence of larvae migration to the lung [19]. Also, a positive association between infection/sensitization and severity of asthma symptoms has been described $[12,20]$. Ascaris infection promotes Th2 responses, increasing total and specific $\operatorname{IgE}[21,22]$ and there is evidence that the strong $\operatorname{IgE}$ response is associated with asthma [13,23]. Since HDM share allergenic components with Ascaris [24] a clinical role by increasing the antibody mediated allergic response is possible [25]. In addition there is evidence from animal models that ascariasis may increase the $\operatorname{IgE}$ responses to bystander antigens, suggesting another mechanism underlying its influence on allergic symptoms. However, the relationship between this IgE hyperresponsivenes and the severity of asthma has not been sufficiently investigated, an important gap considering that about half of people live in the tropics.

Because of the permanent co exposure to HDM allergens and Ascaris infection and the cross reactivity between allergens from these sources, the evaluation of the potential role of IgE response to Ascaris on asthma should include, in addition to adjusting for confounders, the use of both, species-specific and cross reacting allergens. In this study, we aimed to investigate the role of Ascaris and purified allergenic components sensitization on indicators of asthma severity in patients living in a tropical Caribbean city. We also evaluated the influence of sensitization to a nematode specific marker on the strength of the IgE response to mite-specific allergens.

\section{Methods}

\section{Design, location and study population}

This is a cross-sectional study to analyze the relationship between Ascaris sensitization and asthma severity in 313 patients. The study population is from Cartagena de Indias, a tropical city in the Caribbean Coast of Colombia (10 $23^{\prime} 59^{\prime \prime}$ North, $75^{\circ} 30^{\prime} 52^{\prime \prime}$ West) with an average annual temperature of $28^{\circ} \mathrm{C}$ and $80 \%$ of relative humidity. Most inhabitants are poor according to governmental indexes that assess type of housing, overcrowding (three or more people per bedroom), access to basic services, income and school attendance. This socioeconomic stratification ranges from 1 to 6 and $90 \%$ of the study population is grouped in the lowest strata (1 to 3) [26] and shared environmental conditions. The genetic background resulted from racial admixture between Native Americans, Spaniards, and an important proportion (37.9\%) of African ancestry [27]. The study was approved by the Ethics Committee of the University of Cartagena (Cartagena, Colombia). Signed informed consent was obtained from patients or their parents.

\section{Eligibility criteria and enrollment procedures}

Subjects attending to five public primary health care centers and the University Hospital were screened for eligibility by physicians of the research staff between June 2010 and March 2011. These centers serve the lowest social strata in the city. Eligibility criteria were: subjects in the age range of 8 to 70 years who answered affirmatively to the question: Have you ever been diagnosed with asthma? Inclusion in the study depended on the confirmation of asthma diagnosis made by the physician. Patients with chronic obstructive pulmonary disease or another chronic respiratory co-morbidity were excluded as well as those patients belonging to the highest socio-economical strata of the city (4 to 6). Patients received an explanation about the investigation and signed a written informed consent to participate.

\section{Asthma diagnosis and indicators of severity}

Eligible subjects were further interviewed and asthma diagnosis was confirmed in those with at least two respiratory symptoms (cough, wheezing, dyspnea, and nocturnal 
cough/wheezing/dyspnea) or a history of recurrent asthma attacks. These questions were done by staff physicians following a validated questionnaire [28,29]. In addition, using the same questionnaires presence of symptoms such as severe dyspnea, night awakenings and number of ER visits and hospitalizations in the last 12 months were assessed.

\section{Skin prick test}

Skin prick test (SPT) was done in the forearm with a battery of allergen extracts (kindly supplied by Leti; Madrid, Spain) including: B. tropicalis, D. pteronyssinus, Periplaneta americana, Penicillium spp., Aspergillus fumigatus, Alternaria alternata, Artemisia artemisoflia, dog and cat epithelium extracts, histamine phosphate $10 \mathrm{mg} / \mathrm{mL}$ as positive control and allergen diluent as negative control. The test was considered positive if the mean diameter of the wheal at 15 minutes was $>3 \mathrm{~mm}$ than the negative control.

\section{Assessment of lung function}

Spirometry was performed with a Microlab spirometer (Carefusion Corporation, USA) following the American Thoracic Society recommendations [30]. Height and weight were measured; patients were instructed to avoid use of short-acting bronchodilators for at least 12 hours before testing. The best forced expiratory volume in one second (FEV1) and forced vital capacity (FVC) were selected for data analysis of FEV1 and FEV1/FVC ratio. To evaluate bronchodilator responsiveness (BDR), spirometry was performed before and 15 minutes after receiving $200 \mu \mathrm{g}$ (2 puffs) of inhaled salbutamol.

\section{Stool samples and parasitological examination}

Parasitological analyses were done using $0.85 \%$ saline solution and lugol staining; counting helminth eggs were done by the Kato Katz method using a commercial kit (Copro Kit, C\&M Medical, Campinas, Brazil). The results were expressed as egg per gram of feces (e.p.g.). The presence of eggs from geohelminths or parasite visualization was considered diagnostics of active infection. Antecedents of helminthic infection were asked by a questionnaire.

\section{Cloning and expression of recombinant allergens}

Asc s 1 (ABA-1) is an allergen of Ascaris spp. that has been found only in nematodes; it is a member of the polyprotein allergen/antigens with fatty acid-binding properties [31,32]. It has been used as serological marker of Ascaris infection [33-35] and due to its lack of crossreactivity with mite allergens [36] is very useful as a nematode specific diagnostic reagent. Asc 13 is the tropomyosin from Ascaris lumbricoides, cross-reactive with mite orthologs [37]. Recombinant Asc s 1 (kindly supplied by Malcolm Kennedy, University of Glasgow) and Asc 13 were obtained as previously described $[24,38]$. Blo t 5 is a major allergen from B. tropicalis; its lack of cross-reactivity with Ascaris spp. has been demonstrated experimentally [39]. Its nucleotide sequence was amplified from a cDNA library of $B$. tropicalis and the fragment was cloned into a pET100 vector, expressed in BL21 (DE3) cells and purified as a 6xhis tagged protein; its sequence had $100 \%$ of identity with the one reported by Arruda et al. [O96870] [40].

Codon-optimized gene sequences of the tropomyosins Blo t 10 [ABU97466.1] and Der p 10 [AAB69424.1] were synthetized and subcloned into $\mathrm{pET} 45 \mathrm{~b}+$ vector by Genscript (Piscataway, USA). For protein expression, competent Escherichia coli BL21 (DE3) cells were transformed by electroporation and selected on Luria broth (LB) agar plates containing ampicillin. A saturated E. coli culture was inoculated into LB medium with ampicillin, grown at $37^{\circ} \mathrm{C}$ until it reached an $\mathrm{OD}_{600}$ of 0.5 and induced with $1 \mathrm{mM}$ Isopropyl-1- $\beta$-thiogalactopyranoside. After $5 \mathrm{~h}$ of shaking at $37^{\circ} \mathrm{C}$, cells were centrifuged at $3500 \mathrm{rpm}$ during $30 \mathrm{~min}$ at $4^{\circ} \mathrm{C}$. Induced cultures were re-suspended in native buffer $\left(50 \mathrm{mM} \mathrm{NaH}_{2} \mathrm{PO}_{4} 300 \mathrm{mM}\right.$ $\mathrm{NaCl})$ incubated with lysozyme $(1 \mathrm{mg} / \mathrm{ml})$ and then sonicated. Lysates were incubated with Ni-NTA resin (Invitrogen) for one hour, washed with native buffer plus $20 \mathrm{mM}$ imidazole and eluted with native buffer plus $250 \mathrm{mM}$ imidazole as a 6xHis-tagged protein.

\section{Quantification of total and specific $\lg \mathrm{E}$}

Blood samples were taken by venipuncture at the first visit to medical office using anticoagulant-free tubes to obtain serum for antibody determinations. Serum total IgE and specific IgE levels against B. tropicalis, D. pteronyssinus, Der $\mathrm{p} 2$ and $A$. lumbricoides were determined by ImmunoCap system (Phadia100, Thermo, Sweden). A cut-off value of $0.35 \mathrm{kU} / \mathrm{L}$ was used to consider a test as positive. Specific IgE levels to Asc s 1, Blo t 5, Asc 1 3, Blo t 10 and Der p 10 were measured by indirect ELISA, as described previously [24,36]. The cutoff for Blo t 5 and Asc s 1 was defined as an optical density (OD) value greater than 0.130 . In the case of the three tropomyosins, the OD cut-off value was 0.156 .

\section{Clinical phenotypes and other outcomes}

The following outcomes were evaluated: Indicators of asthma severity: occurrence of severe dyspnea episodes, night awakenings events, $>4$ ER visits and hospitalizations during the last year. BDR: a change greater than $12 \%$ in the predicted FEV1 value after bronchodilator administration. HDM sensitization: A positive IgE result to B. tropicalis or D. pteronyssinus extracts. Ascaris sensitization: A positive IgE result to Ascaris extract. 
Atopy: at least one positive SPT to any of the tested allergens.

\section{Statistical analysis}

Most analyses were done using SPSS version 13.0 (Chicago, IL, USA). Frequency rates and their 95\% confidence intervals (CI) were obtained with Epidat 3.1 (Xunta de Galicia, PAO/WHO). Total and specific IgE values were not normally distributed and they were therefore reported as the median value and its interquartile range, except total IgE (geometric mean). Mann-Whitney $U(\mathrm{MW})$ test was used for comparison of continuous variables. Differences between proportions were analyzed by Pearson chi-squared test (or Fisher exact test when appropriate). Chochran-Armitage test was used for trend association analysis.

Univariate and multivariate binary logistic regression were used to analyze the relationships of exposures and outcomes. Sensitizations to HDM, Ascaris or the recombinant allergens were included in the models as predictor/exposures. Indicators of disease severity and lung function parameters were analyzed as outcomes. Significant associations in the univariate analysis were further explored in multivariate models including age, gender, socio-economical strata, tobacco consumption and cohabitation with a smoker as covariates. Additionally, HDM sensitization or atopy was included as covariates in separate models. Crude (OR) and adjusted odds ratios (aOR), their $95 \% \mathrm{CI}$ and p-values were calculated.

\section{Sample size and power}

Power was calculated assuming an independent casecontrol design and expressing the alternative hypothesis as Odds Ratio $(\psi)$. For a given risk factor the calculation was done by setting type I error probability at $\alpha=0.05$, number of cases (n), probability of exposure among controls $(\rho 0)$, and the ratio of controls/ cases (m) [41].

A priori calculations of study power were done with published data of $57.8 \%$ of Ascaris sensitization in our population [42] and prevalence rates of asthma severity indicators, estimated within a national epidemiological survey [28]. With a sample size $\mathrm{n}=330$, assuming odds ratio of 2 , power values $>0.8$ were obtained to detect associations between Ascaris sensitization and any of these outcomes.

\section{Results}

\section{Characteristics of the study population}

From 336 recruited individuals, one did not meet criteria for asthma diagnosis and 22 were excluded (Figure 1). Socio-demographic characteristics and severity of symptoms of the excluded subjects were similar to those that continued in the study. In total, 313 patients were

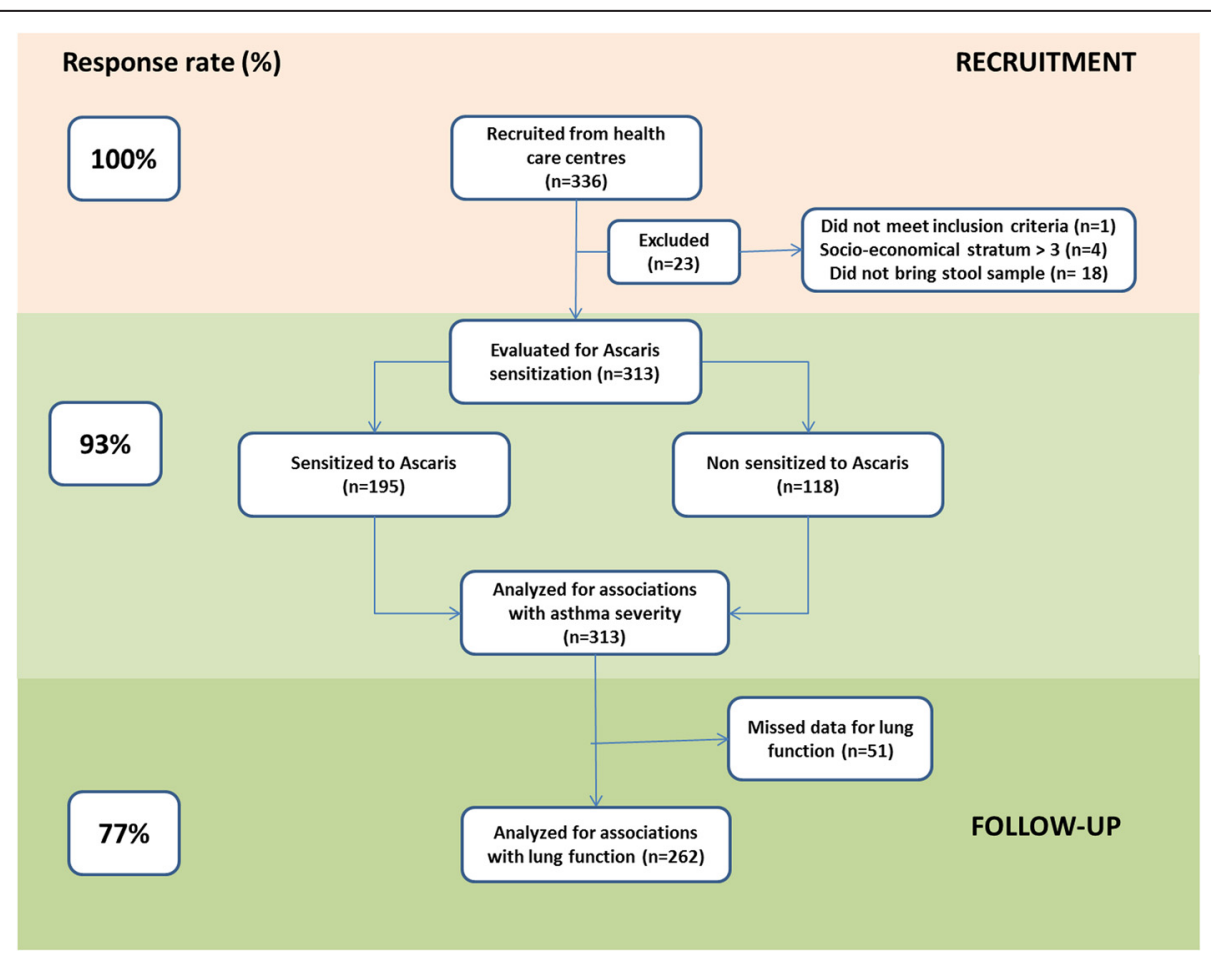

Figure 1 Flow-chart of data collection and response rates in the study. Responses rates (left boxes) are shown as a percentage, relative to the total number of recruited individuals. Exclusion criteria, applied during recruitment, and missing data cases (right boxes) are also detailed. 
included, Ascaris sensitization was evaluated in all of them but lung function data were obtained from 262. Reasons for not performing the test were use of $\beta 2$ agonist drugs in the previous 12 hours and no collaboration of the patient to follow the instructions.

Power estimates for the analyzed outcomes were as follows: nocturnal awakenings: 0.60 (59.6\% of exposed subjects in cases vs. $58.7 \%$ in control group), severe dyspnea: 0.75 (69.2\% of exposed subjects in cases vs. $54.5 \%$ in control group), hospitalizations in the last year: 0.09 (68.4\% of exposed subjects in cases vs. $63.3 \% \%$ in control group), $>4$ ER visits in the last year: 0.82 (75.6\% of exposed subjects in cases vs. $60 \% \%$ in control group), BDR: 0.63 (69.0 of exposed subjects in cases vs. $59.3 \%$ in control group).

Characteristics of the study population are shown in Table 1. Ascaris sensitization was frequent (62.3\%, 95\% CI: 56.8 - 67.8), more common in males and inversely proportional to socio-economical stratum. Also, it was associated with atopy, especially with a positive SPT to any of the two HDM species. Prevalence of active ascariasis was low (3.8\%, 95\% CI: $1.7-6.0$, mean of intensity: 19.332 e.p.g., range: 78 to 156.000). Trichuris trichuria infection was less frequent $(1.9 \%$, 95\% CI: 0.4 - 3.4). Ascaris sensitization was positively associated with Ascaris infection (Fisher exact test: $\mathrm{p}=0.04$ ) or self-reported helminth expulsion in the past $\left(\mathrm{x}^{2}: 4.20, \mathrm{p}=0.04\right)$. Infected patients had higher Ascaris-specific IgE levels than those with a negative stool examination $(\mathrm{p}=0.01)$. Furthermore, IgE sensitization to Asc s 1 was high (70.3\%, 95\% CI: 65.1 - 75.5).

Most patients reported symptoms of uncontrolled asthma Atopic asthma was common (76.5\%, 95\% CI: 71.6 - 81.4) and indicators of uncontrolled asthma were frequently observed (Table 2). Most patients used short-acting $\beta 2$ receptor agonist as a "control medication" $(79.9 \%, 95 \%$ CI: 75.3 - 84.5). Current use of oral corticosteroids was more common (42.6\%, 95\% CI: 36.9 - 48.3) than that of inhaled corticosteroids (31.5\%, 95\% CI: 26.1 - 36.8). There were no significant differences in the use of these drugs among socioeconomic strata, except for oral corticosteroids, whose usage was more frequent in the poorest stratum (trend test: 5.72, $\mathrm{p}=0.02$ ); those belonging to stratum 1 used oral corticosteroids 2.19 more times (95\% CI: 1.33 - 3.63) than the other strata (stratum 1 vs. $2+3$ ).

Ascaris and house dust mite sensitization were associated to indicators of asthma severity

We analyzed the relationship of Ascaris and HDM sensitization with clinical indicators of asthma severity (Table 2). After adjusting by covariates, sensitization to Ascaris was associated with "having episodes of severe dyspnea" and "ER attendance $>4$ times during the last

Table 1 Socio-demographic characteristics of the study population

\begin{tabular}{|c|c|c|c|c|}
\hline \multirow[b]{2}{*}{ Variables } & \multirow[b]{2}{*}{ All patients } & \multicolumn{2}{|c|}{ Ascaris sensitization } & \multirow[b]{2}{*}{ p-value } \\
\hline & & Yes $(n=195)$ & No $(n=118)$ & \\
\hline Gender (male) & $28.1(23.0-33.3)$ & $36.9(29.9-44.0)$ & $13.6(7.0-20.2)$ & $<0.0001$ \\
\hline Age $($ mean $\pm S D)$ & $32.9 \pm 16.9$ & $35.96 \pm 15.7$ & $31.1 \pm 17.3$ & 0.01 \\
\hline \multicolumn{5}{|l|}{ Socio-economical strata* } \\
\hline 1 & $62.3(56.8-67.8)$ & $67.7(60.9-74.5)$ & 53.4. (44.0-62.8) & \\
\hline 2 & $31.6(26.3-36.9)$ & $29.2(22.6-35.9)$ & 35.6. $(26.5-44.7)$ & $<0.01$ \\
\hline 3 & $6.1(3.3-8.9)$ & $3.1(0.4-5.8)$ & $11.0(4.9-17.1)$ & \\
\hline Smoking habit & $5.1(2.5-7.7)$ & $3.4(0.6-5.2)$ & $6.2(4.3-16.1)$ & 0.42 \\
\hline Co-habitation with a smoker & $26.5(21.5-31-6)$ & $30.8(24.0-37.5)$ & $19.5(11.9-27.1)$ & 0.02 \\
\hline Current Ascaris infection & $3.8(1.7-6.0)$ & $6.2(2.5-9.8)$ & $0(0)$ & 0.04 \\
\hline Antecedent of worm expulsion & $62.3(56.8-67.8)$ & $66.7(59.8-73.5)$ & $55.1(45.7-64.5)$ & 0.04 \\
\hline Allergic rhinitis & $85.6(81.6-89.7)$ & $87.2(82.2-92.1)$ & $83.1(75.9-90.2)$ & 0.31 \\
\hline Atopy (>1 positive SPT) & $79.9(74.4-85.4)$ & $84.2(77.8-90.6)$ & $72.9(62.9-83.0)$ & 0.04 \\
\hline Sensitization to $B$. tropicalis & $67.4(62.172 .8)$ & $84.6(79.3-90.0)$ & $39.0(29.8-48.2)$ & $<0.0001$ \\
\hline Sensitization to $D$. pteronyssinus & $60.7(55.1-66.3)$ & $75.4(69.1-81.7)$ & $36.4(27.3-45.6)$ & $<0.0001$ \\
\hline Total lgE キ† & $349.436 \pm 1177.4$ & $585.4 \pm 1412.1$ & $149.0 \pm 201.3$ & $<0.0001$ \\
\hline Specific IgE to B. tropicalist & $2.37 \pm 30.9$ & $11.98 \pm 34.99$ & $0.13 \pm 15.52$ & $<0.0001$ \\
\hline Specific IgE to $D$. pteronyssinus $†$ & $0.94 \pm 34.6$ & $4.04 \pm 39.27$ & $0.09 \pm 21.12$ & $<0.0001$ \\
\hline
\end{tabular}

Frequency rates (\%) for categorical variables are shown. Their $95 \%$ confident intervals are shown in parenthesis.

*Trend analysis.

‡ Geometric mean (standard deviation of mean) are reported.

†Comparison by Mann-Whitney U Test. 
Table 2 Clinical indicators of disease severity: univariate analysis

\begin{tabular}{|c|c|c|c|c|c|c|c|}
\hline \multirow[t]{2}{*}{ Outcomes } & \multirow{2}{*}{$\begin{array}{l}\text { All } \\
\text { patients }\end{array}$} & \multicolumn{3}{|c|}{ Sensitization to Ascaris } & \multicolumn{3}{|c|}{ HDM sensitization } \\
\hline & & Yes & No & p-value & Yes & No & p-value \\
\hline Episodes of severe dyspnea & $201(64.2)$ & $136(69.7)$ & $65(55.1)$ & 0.01 & $147(65.3)$ & $54(61.4)$ & 0.51 \\
\hline Nocturnal awakenings & $272(86.9)$ & $169(86.7)$ & $103(87.3)$ & 0.53 & $201(89.3)$ & $71(80.7)$ & 0.04 \\
\hline$>4$ ER visits in the last year & $78(24.9)$ & $58(29.7)$ & $20(16.9)$ & 0.01 & $59(26.2)$ & $19(21.8)$ & 0.34 \\
\hline Hospitalizations in the last year & $38(12.1)$ & $25(12.8)$ & $13(11.1)$ & 0.53 & $30(13.3)$ & $8(9.1)$ & 0.30 \\
\hline
\end{tabular}

Significant associations are in bold.

year", even when HDM sensitization was included in the model (Table 3, Model 2). After stratification by atopy, the relationship of Ascaris sensitization with "ER attendance $>4$ times during the last year" only remained significant in atopic subjects (aOR: 4.07, 95\% CI: $1.14-$ 14.49; $\mathrm{p}=0.03)$. HDM sensitization was associated with "having nocturnal awakenings" (aOR: 2.09 95\% CI: 1.03 4.28, $\mathrm{p}=0.04$ ), independently of Ascaris sensitization (aOR: 2.68, 95\% CI: $1.21-5.95, \mathrm{p}=0.02$ ).

Regarding medication for asthma control, use of short-action $\beta_{2}$ agonist inhalers was associated with Ascaris sensitization (aOR: 1.86, 95\% CI: 1.01-3.48, $\mathrm{p}=0.05$ ), the significance was stronger in the subgroup of HDM-sensitized patients (aOR: 2.59 95\% CI: $1.19-5.62, \mathrm{p}=0.016)$. There were no differences in the use of inhaled or oral corticosteroids according to Ascaris sensitization. HDM sensitization was neither associated to any of these outcomes.

We also evaluated the effect of sensitization to molecular components from Ascaris (Asc s 1 and Asc 13 ) and HDM (Blo t 5, Blo t 10, Der p 2 and Der p 10) on indicators of asthma severity. Sensitization to Blo t 5 (aOR: 1.93 95\% CI: 1.12-3.33, p=0.02), Asc s 1 (aOR: $2.4795 \%$ CI: $1.10-5.71$, $\mathrm{p}=0.03$ ), Der p 10 (aOR: 2.44 95\% CI: $1.19-4.98, \mathrm{p}=0.01$ ) and Asc 13 (aOR: 2.23 95\% CI: $1.10-4.50, \mathrm{p}=0.02$ ) were significantly associated with ER attendance $>4$ times in the last year after adjustment by age, gender, tobacco exposure, socio-economical strata and atopy. No significant associations were found among sensitization to Der p 2 and any indicator of asthma severity (data not shown).

\section{HDM sensitization was associated with bronchodilator} response

Descriptive information about lung function is shown in Table 4. Neither Ascaris, nor HDM sensitization were associated to predicted basal or post bronchodilator (BD) FEV1 values or FEV1/FVC indexes; however, BDR was significantly associated with HDM sensitization. In multivariate analysis, after adjustment by gender, age and cigarette exposition, Ascaris sensitization was also associated to this outcome (aOR: 1.87, 95\% CI: $1.05-3.31 ; \mathrm{p}=0.03$ ) however, the significance disappeared after including HDM-sensitization in the model. In contrast, HDM sensitization was associated with BDR independently of Ascaris sensitization (aOR: 2.67, 95\% CI: 1.33 - 5.32, $\mathrm{p}=0.01$ ). Furthermore, a significant association was also observed with Der p 2 sensitization (aOR: 2.24: 1.25-4.02, $\mathrm{p}=0.01$ ) but not with other recombinant allergens. Since BDR has been associated with indicators of severity [43] we further explored this relationship in our population, finding that it was associated with ER attendance $\left(\chi^{2}=6.44, p=0.01\right)$ and nocturnal symptoms $\left(x^{2}=8.80, p=0.003\right)$.

\section{IgE response to Ascaris correlates with house dust mite specific lgE}

Ascaris specific IgE values were highly correlated with those against B. tropicalis (Spearman rho: 0.63, $\mathrm{p}<0.001$ ) or D. pteronyssinus (Spearman rho: $0.53 \mathrm{p}<0.001$ ) (Figure 2). The IgE response to the highly crossreactive tropomyosin allergen group was also explored. Sensitization rates to the tropomyosins from Ascaris (Asc 1 3: 24.0\%, 95\% CI: 19.1 - 28.9) and HDM were similar (Blo t 10: 26.4\% 95\% CI: 21.3 - 31.5, Der p 10: $26.1 \%$ 21.0-31.1). Specific IgE values among the three allergens were highly correlated (Spearman rho coefficients: Asc $13-$ Der p $10=0.58$, Asc $13-$ Blo $t$ $10=0.57$, Blo t $10-$ Der p $10=0.85, \mathrm{p}<0.001$ in all cases) but they were significantly higher for HDM tropomyosins.

Table 3 Ascaris sensitization and indicators of asthma severity: multivariate logistic regression analysis

\begin{tabular}{|c|c|c|c|c|c|c|}
\hline \multirow[t]{2}{*}{ Outcomes } & \multicolumn{3}{|c|}{ Model 1} & \multicolumn{3}{|c|}{ Model 2} \\
\hline & $\overline{\mathrm{OR}}$ & $95 \% \mathrm{Cl}$ & p-value & OR & $95 \% \mathrm{Cl}$ & $\mathrm{p}$-value \\
\hline Episodes of severe dyspnea & 1.90 & $1.13-3.18$ & 0.02 & 1.90 & $1.08-3.34$ & 0.03 \\
\hline$>4$ ER visits in the last year & 2.31 & $1.26-4.22$ & 0.01 & 2.23 & $1.15-4.30$ & 0.02 \\
\hline Bronchodilator responsiveness & 1.87 & $1.05-3.31$ & 0.03 & 1.36 & $0.73-2.52$ & 0.33 \\
\hline
\end{tabular}

Model 1: Adjusted by age, gender, socioeconomic strata and tobacco exposition. 
Table 4 Influence of HDM or Ascaris sensitization on lung function parameters

\begin{tabular}{|c|c|c|c|c|c|c|c|}
\hline \multirow[t]{2}{*}{ Outcomes } & \multirow{2}{*}{$\begin{array}{l}\text { All patients } \\
(n=262)\end{array}$} & \multicolumn{3}{|c|}{ Sensitization to Ascaris } & \multicolumn{3}{|c|}{ HDM sensitization } \\
\hline & & Yes & No & p-value & Yes & No & p-value \\
\hline \multicolumn{8}{|l|}{ Continuous variables (mean \pm SD) } \\
\hline Predicted baseline FEV $_{1}(\%)$ & $71.40 \pm 20.61$ & $70.38 \pm 20.50$ & $73.02 \pm 20.75$ & 0.31 & $71.03 \pm 20.78$ & $72.38 \pm 20.27$ & 0.64 \\
\hline Predicted post BD FEV 1 (\%) & $77.70 \pm 18.60$ & $77.30 \pm 18.11$ & $78.32 \pm 19.41$ & 0.67 & $77.89 \pm 18.60$ & $77.21 \pm 18.70$ & 0.79 \\
\hline FEV1/FVC (\%) & $86.08 \pm 15.80$ & $85.42 \pm 16.07$ & $87.14 \pm 15.37$ & 0.39 & $85.17 \pm 15.88$ & $88.48 \pm 15.42$ & 0.13 \\
\hline \multicolumn{8}{|l|}{ Categorical [n (\%)] } \\
\hline Predicted baseline FEV1 $<80 \%$ & $158(60.31)$ & $100(62.5)$ & $58(56.9)$ & 0.36 & $117(61.6)$ & $41(56.9)$ & 0.49 \\
\hline Bronchodilator responsiveness & $100(38.2)$ & $67(34.4)$ & $33(28.0)$ & 0.11 & $81(42.6)$ & $19(26.4)$ & 0.01 \\
\hline
\end{tabular}

\section{Ascaris sensitization influences IgE responses to mite specific allergens}

As shown in Figure 3, significantly higher IgE levels to HDM specific markers were found in Ascaris sensitized patients compared to non-sensitized subjects (Blo t 5: $0.47 \pm 0.58$ vs. $0.17 \pm 0.16$ OD, $\mathrm{p}<0.001$; Der p 2: $12.90 \pm 25.52$ vs. $3.54 \pm 13.80 \mathrm{kU} / \mathrm{L}, \mathrm{p}<0.001)$.

\section{Discussion}

In this work, we investigated the effects of the IgE response to Ascaris on the severity of asthma symptoms in patients from a socio-economically deprived population of the tropics. Asthma was mainly atopic and indicators of uncontrolled disease, as well as the inappropriate use of control medication, were very frequent. In spite of a low prevalence of current Ascaris infection (as detected by stool examination), IgE sensitization to this helminth was high and associated to poverty. Also, it was more frequent in males, a finding previously described [12]. Because of coexposure and their cross-reactivity [25,36] anti-Ascaris specific IgE levels and those against HDM were highly correlated. As in other reports, Ascaris sensitization was associated with different clinical indicators of asthma severity $[10,12,20]$, but importantly, this is the first study evaluating the antibody responses with purified allergens, further supporting the results obtained with the complete extracts.

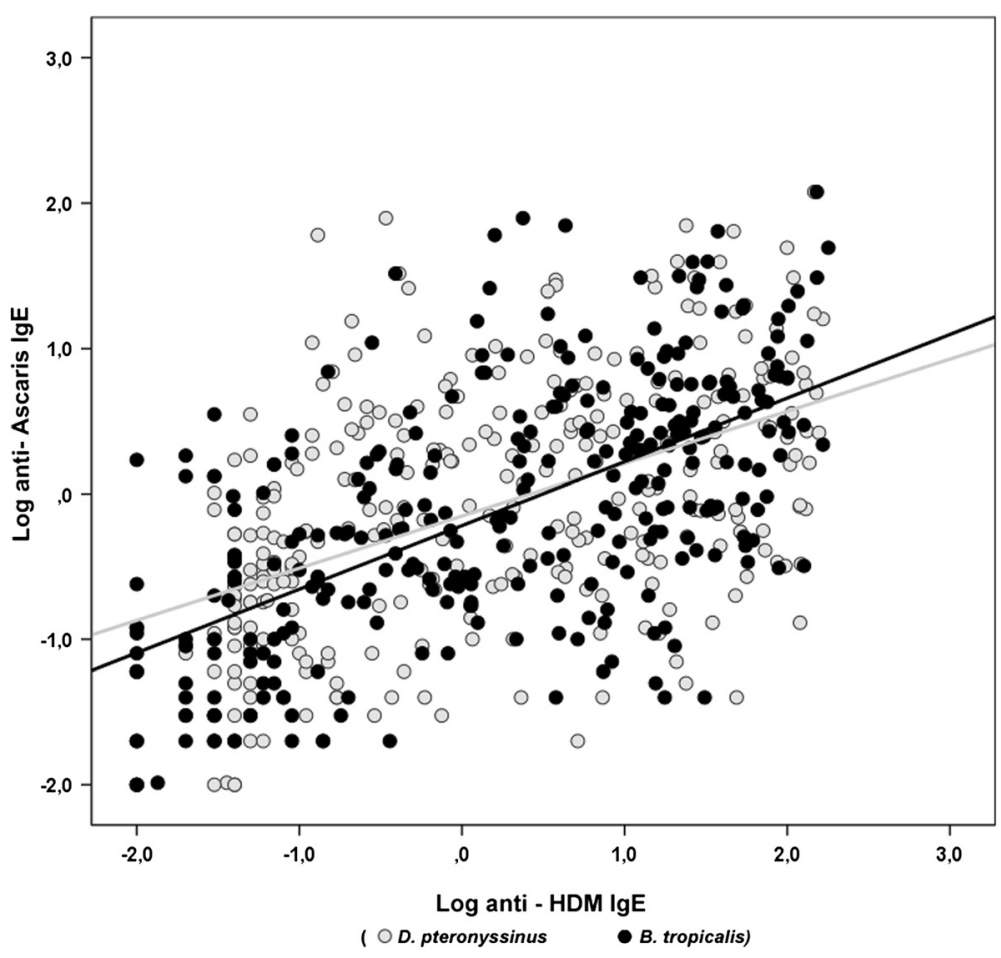

Figure 2 Correlation among Ascaris, B. tropicalis and D. pteronyssinus - specific lgE values. Log transformed values were represented in this superimposed dispersion plot; linear regression slopes for B. tropicalis - Ascaris (black) and D. pteronyssinus - Ascaris (grey) [X-Y] pairs are also shown. 

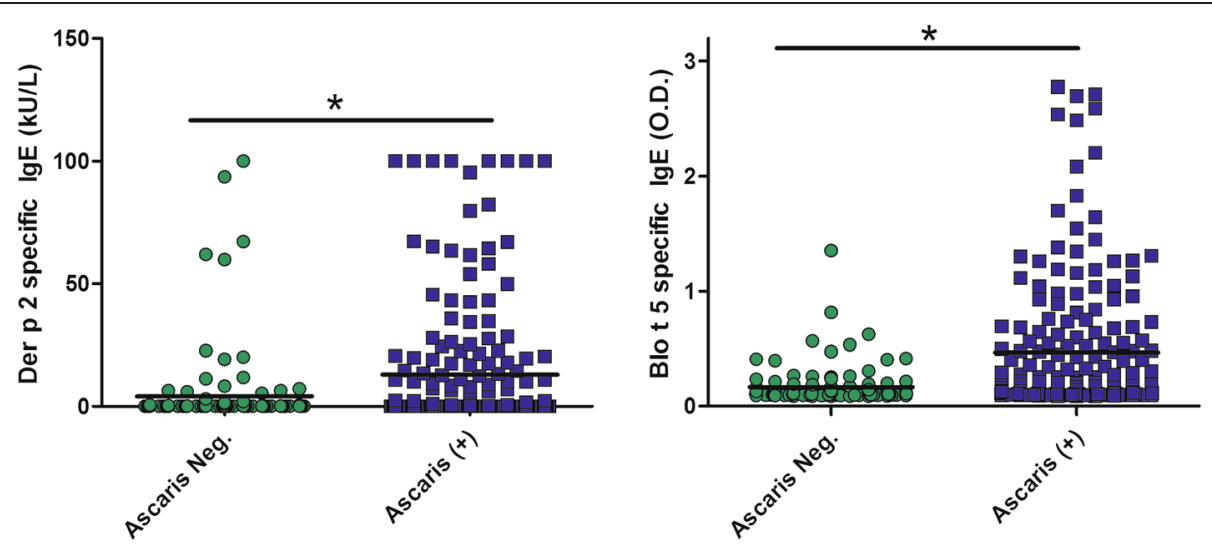

Figure $3 \mathrm{lgE}$ responses to HDM-specific allergens according to Ascaris sensitization. IgE response to Der $p$ 2, a specific marker for Dermatophagoides spp. and Blo t 5, a specific marker for Blomia tropicalis among Ascaris sensitized and non sensitized (Ascaris neg.) subjects. * $p<0.001$.

Anti-Ascaris IgE response was used as an indicator of infection because it is well known that diagnosis of ascariasis by stool examination, especially in places with low-burden infections, is limited by its low sensitivity [44,45]. Anti-Ascaris and anti-Asc s 1 IgE antibodies may identify cases of current infection as well as previous exposure [46] and our main interest was to evaluate the relationship of this IgE response with indicators of asthma severity. The low rate of positive stool examination precluded an analysis of its association with disease severity.

Clinical indicators of asthma severity were very frequent in this population and this could be related to low level of asthma control, as suggested by the underuse of appropriate treatment [47]. Ascaris sensitization was associated with increased odds of suffering severe dyspnea episodes and ER attendance, but it was also significantly related to poverty. Therefore, it is possible that socio-economic conditions might explain the observed results rather than a direct biological effect of ascariasis on symptoms severity, however, this variable was not significantly associated with any of the indicators of disease severity. Moreover, there were no differences in the use of control medication among socio-economical strata, but use of oral corticosteroids was more common among the poorest. Accordingly, the relationship of Ascaris sensitization with the severity of symptoms was independent of medication access due to socioeconomic conditions.

Cross reactive IgE response to mites and helminths, as well as co-exposure to both sources may be confounding factors when assessing the relationship between ascariasis and allergic diseases [25,36]. For example, there is usually strong co-linearity between sensitization to Ascaris and HDM. It has been argued that adjusting for HDM sensitization in the multivariate logistic regression model when analyzing the effects of Ascaris sensitization is too conservative [12]. However, in our study, most associations between Ascaris sensitization and asthma severity remained significant after adjusting by HDM sensitization. Also, when using the nematode specific molecular component Asc s 1, multivariate analysis showed a significant association with ER attendance.

Previous studies have found that Ascaris sensitization is a risk factor for increased asthma severity or related outcomes [12,20]. Deworming of Ascaris-infected children was associated with improvement of asthma symptoms and reduction of controller therapy [48]. In children from rural areas of Venezuela the percentage of FEV1 predictive values (a marker of disease severity) correlated inversely with anti-A. lumbricoides IgE levels [10]. Hunninghake et al. also found significant associations between Ascaris sensitization and indicators of asthma severity (airway responsiveness, hospitalizations and BDR) in children from Costa Rica living in an urban setting with low burden of ascariasis; however, only the association with BDR was significant after adjustment by HDM sensitization [12]. In contrast, in our study, associations were found with ER attendance, severe dyspnea episodes and BDR, the latter, non significant after correction.

There are reasons to think that Ascaris sensitization may increase severity of symptoms in asthmatic patients. Several experimental and epidemiological findings [14,15] support that ascariasis may enhance the IgE response, not only to parasite-derived antigens but also to bystander antigens [49], such as aeroallergens [50]. In fact, our study shows that higher IgE levels to the HDM-specific allergens Der p 2 and Blo t 5 were found in Ascaris sensitized patients. Therefore, it is possible that exposure to Ascaris promotes allergic responses and in turn asthmatic symptoms by increasing Th2 cytokine production [51] as well as IgE synthesis to parasite components and environmental allergens $[52,53]$. The induction of parasite-specific IgE antibodies may have biological impact through specific or cross-reactive 
antibody responses. Supporting this idea, sensitization to Asc s 1, but also to Ascaris and HDM tropomyosins were identified as risk factors for ER attendance. It is expected that these promoting effects operate especially in individuals genetically predisposed to develop IgE-mediated inflammation, which could explain why the relationship of Ascaris sensitization with ER attendance only maintained it significance in the group of atopics.

During active infection, migration of Ascaris to the lungs may also increase the severity of asthma symptoms. Direct exposure to parasite allergens expressed during the larval stage that reach the lungs (e.g. Asc 1 3 and Asc s 1) [31,54] may trigger asthma exacerbations through IgE-dependent mechanisms. The direct effect on pro-inflammatory cytokines on the airways should also be considered because epithelial damage induced by parasite invasion causes overexpression of some "alarmin" cytokines that may promote the Th2 responses [55,56] and asthma severity [57]. For example, it has been shown that stimulation of peripheral blood monocyte cells with Ascaris antigens induces IL-17 and IL-33 production in parasite-exposed individuals [58]. There is no certainty about when immune response totally eliminate Ascaris infection in humans, but experimental data from immunized pigs exposed to Ascaris eggs indicate that the infection is controlled at an early stage (L2-L3 larvae) by an effective immune response that kill the parasite in the intestinal mucosa. This inflammatory response was characterized by cellular infiltration of eosinophils and mast cells and accompanied by over expression of Th2 cytokines in the intestine [59]. This could happen in humans, inducing systemic responses even when the larvae do not reach the lung.

In regard to lung function the IgE response to Ascaris was only associated to BDR, however it did not remain significant after correction by HDM sensitization. Other studies have shown that BDR correlates with eosinophilic inflammation, atopy and bronchial hyper reactivity $[43,60]$ and is associated to a good response to controller therapy [61]. We found that BDR was related to some indicators of asthma severity but it seems that HDM allergy is the main determinant of this phenotype.

Several limitations of this study should be discussed. Although asthma diagnosis was done with standard clinical and functional pulmonary tests, in some cases spirometry could not be done, then, power of the study was not sufficient to detect possible associations of Ascaris IgE with lung function parameters. In addition, we only explored the association between Ascaris sensitization and clinical indicators of asthma severity, the use of biological markers would have been of help to better characterize the severity of inflammation.

\section{Conclusions}

In this population of the tropics, IgE sensitization to Ascaris and cross-reactive tropomyosins was frequent and associated with clinical indicators of asthma severity. The significant relationship between sensitization to the nematode-specific marker Asc s 1 and ER attendance supports these findings. Moreover, ascariasis seems to increase the IgE responses to mite specific allergens in humans.

\section{Abbreviations}

HDM: House dust mites; ER: Emergency room; SPT: Skin prick test; FEV1: Forced expiratory volume in one second; FVC: Forced vital capacity; e.p.g.: Egg per gram of feces; OD: Optical density; BDR: Bronchodilator responsiveness.

\section{Competing interests}

We report no conflicts of interest.

\section{Authors' contributions}

LC conceived the investigation, designed the epidemiological study, supervised the general aspects of the work, analyzed the data and wrote the manuscript. JZ conceived the investigation, designed the epidemiological study, contributed with the clinical work, analyzed data and wrote the manuscript. EB organized and performed the clinical work, managed databases, collected biological samples and contributed to manuscript writing. AA performed the parasitological examinations and analysis of data and revised the manuscript. DM performed the lgE serological analysis and revised the manuscript. All authors read and approved the final manuscript.

\section{Acknowledgements}

We thank all patients that voluntarily participated in this study and the staff of the E.S.E. Cartagena de Indias, by their administrative support. We are grateful to Malcolm Kennedy for providing us with the ABA-1 clone. This research was supported by a grant (Contract 602-2009) from the Colombian Government (Departamento Administrativo de Ciencia y Tecnología e Innovación, Colciencias), University of Cartagena and Fundemeb.

\section{Author details}

${ }^{1}$ Institute for Immunological Research, University of Cartagena, Cartagena, Colombia. ${ }^{2}$ Foundation for the Development of Medical and Biological Sciences (Fundemeb), Cartagena, Colombia. ${ }^{3}$ Department of Microbiology, Faculty of Medicine, University of Cartagena, Cartagena, Colombia.

Received: 2 October 2014 Accepted: 21 January 2015

Published online: 04 March 2015

\section{References}

1. Eder W, Ege MJ, von Mutius E. The asthma epidemic. N Engl J Med. 2006:355:2226-35.

2. Caraballo L: Ascaris and Allergy. In Ascaris: the neglected parasite. Edited by Holland CV: Elsevier; 2013: 21-50.

3. Caraballo L, Acevedo N. New allergens of relevance in tropical regions: the impact of Ascaris lumbricoides infections. WAO J. 2011;4:77-84.

4. Pullan RL, Smith JL, Jasrasaria R, Brooker SJ. Global numbers of infection and disease burden of soil transmitted helminth infections in 2010. Parasites \& Vectors. 2014;7:37.

5. Chammartin F, Scholte RG, Guimaraes LH, Tanner M, Utzinger J, Vounatsou P. Soil-transmitted helminth infection in South America: a systematic review and geostatistical meta-analysis. Lancet Infect Dis. 2013;13:507-18.

6. Carneiro FF, Cifuentes E, Tellez-Rojo MM, Romieu I. The risk of Ascaris lumbricoides infection in children as an environmental health indicator to guide preventive activities in Caparao and Alto Caparao, Brazil. Bull World Health Organ. 2002:80:40-6.

7. Rinne S, Rodas EJ, Galer-Unti R, Glickman N, Glickman LT. Prevalence and risk factors for protozoan and nematode infections among children in an Ecuadorian highland community. Trans R Soc Trop Med Hyg. 2005;99:585-92. 
8. Pino LA, Matinella L, Morales G. [The size polymorphism of the cercariae of a Venezuelan strain of Schistosoma mansoni]. Rev Soc Bras Med Trop. 1999;32:443-6.

9. Agudelo-Lopez S, Gomez-Rodriguez L, Coronado X, Orozco A Valencia-Gutierrez CA, Restrepo-Betancur LF, et al. [Prevalence of intestinal parasitism and associated factors in a village on the Colombian Atlantic Coast]. Rev Salud Publica (Bogota). 2008;10:633-42.

10. Hagel I, Cabrera M, Hurtado MA, Sanchez P, Puccio F, Di Prisco MC, et al. Infection by Ascaris lumbricoides and bronchial hyper reactivity: an outstanding association in Venezuelan school children from endemic areas. Acta Trop. 2007;103:231-41.

11. Acevedo N, Sanchez J, Zakzuk J, Bornacelly A, Quiroz C, Alvarez A, et al. Particular characteristics of allergic symptoms in tropical environments: follow up to 24 months in the FRAAT birth cohort study. BMC Pulm Med. 2012;12:13.

12. Hunninghake GM, Soto-Quiros ME, Avila L, Ly NP, Liang C, Sylvia JS, et al. Sensitization to Ascaris lumbricoides and severity of childhood asthma in Costa Rica. J Allergy Clin Immunol. 2007;119:654-61.

13. Obihara CC, Beyers N, Gie RP, Hoekstra MO, Fincham JE, Marais BJ, et al. Respiratory atopic disease, Ascaris-immunoglobulin E and tuberculin testing in urban South African children. Clin Exp Allergy. 2006;36:640-8.

14. Leonardi-Bee J, Pritchard D, Britton J. Asthma and current intestinal parasite infection: systematic review and meta-analysis. Am J Respir Crit Care Med. 2006;174:514-23.

15. Palmer $\sqcup$, Celedon JC, Weiss ST, Wang B, Fang Z, Xu X. Ascaris lumbricoides infection is associated with increased risk of childhood asthma and atopy in rural China. Am J Respir Crit Care Med. 2002;165:1489-93.

16. Dold S, Heinrich J, Wichmann HE, Wjst M. Ascaris-specific IgE and allergic sensitization in a cohort of school children in the former East Germany. J Allergy Clin Immunol. 1998;102:414-20.

17. Scrivener S, Yemaneberhan H, Zebenigus M, Tilahun D, Girma S, Ali S, et al. Independent effects of intestinal parasite infection and domestic allergen exposure on risk of wheeze in Ethiopia: a nested case-control study. Lancet. 2001;358:1493-9.

18. Cooper PJ, Chico ME, Rodrigues LC, Ordonez M, Strachan D, Griffin GE, et al. Reduced risk of atopy among school-age children infected with geohelminth parasites in a rural area of the tropics. J Allergy Clin Immunol. 2003;111:995-1000.

19. Phills JA, Harrold AJ, Whiteman GV, Perelmutter L. Pulmonary infiltrates, asthma and eosinophilia due to Ascaris suum infestation in man. N Engl J Med. 1972;286:965-70

20. Ripa C, Bahnea RG, Cojocaru I, Luca MC, Leon M, Luca M. [Sensitization to ascaris lumbricoides and asthma severity in children]. Revista Medico-Chirurgicala a Societatii de Medici si Naturalisti din Lasi. 2011;115:387-91.

21. Zakzuk J, Acevedo N, Cifuentes L, Bornacelly A, Sanchez J, Ahumada V, et al. Early life IgE responses in children living in the tropics: a prospective analysis. Pediatr Allergy Immunol. 2013;24:788-97.

22. Levin ME, Le Souef PN, Motala C. Total IgE in urban Black South African teenagers: the influence of atopy and helminth infection. Pediatr Allergy Immunol. 2008;19:449-54.

23. Takeuchi H, Zaman K, Takahashi J, Yunus M, Chowdhury HR, Arifeen SE, et al. High titre of anti-Ascaris immunoglobulin E associated with bronchial asthma symptoms in 5-year-old rural Bangladeshi children. Clin Exp Allergy. 2008;38:276-82.

24. Acevedo N, Erler A, Briza P, Puccio F, Ferreira F, Caraballo L. Allergenicity of Ascaris lumbricoides tropomyosin and lgE sensitization among asthmatic patients in a tropical environment. Int Arch Allergy Immunol. 2009;154:195-206

25. Acevedo N, Caraballo L. IgE cross-reactivity between Ascaris lumbricoides and mite allergens: possible influences on allergic sensitization and asthma. Parasite Immunol. 2011;33:309-21

26. RuedaFA E. Will Today's Poor be Tomorrow's Poor? Colombia: Determinants of the Poverty and Magnitude of the Vulnerability in Cartagena De Indias; 2009

27. Vergara C, Caraballo L, Mercado D, Jimenez S, Rojas W, Rafaels N, et al. African ancestry is associated with risk of asthma and high total serum lgE in a population from the Caribbean Coast of Colombia. Hum Genet. 2009:125:565-79.

28. Dennis RJ, Caraballo L, Garcia E, Rojas MX, Rondon MA, Perez A, et al. Prevalence of asthma and other allergic conditions in Colombia 2009-2010: a cross-sectional study. BMC Pulm Med. 2012;12:17.
29. Dennis R, Caraballo L, Garcia E, Caballero A, Aristizabal G, Cordoba H, et al. Asthma and other allergic conditions in Colombia: a study in 6 cities. Ann Allergy Asthma Immunol. 2004;93:568-74.

30. Miller MR, Hankinson J, Brusasco V, Burgos F, Casaburi R, Coates A, et al. Standardisation of spirometry. Eur Respir J. 2005;26:319-38.

31. Xia Y, Spence HJ, Moore J, Heaney N, McDermott L, Cooper A, et al. The ABA-1 allergen of Ascaris lumbricoides: sequence polymorphism, stage and tissue-specific expression, lipid binding function, and protein biophysical properties. Parasitology. 2000;120(Pt 2):211-24.

32. Kennedy MW, Brass A, McCruden AB, Price NC, Kelly SM, Cooper A. The ABA-1 allergen of the parasitic nematode Ascaris suum: fatty acid and retinoid binding function and structural characterization. Biochemistry. 1995:34:6700-10.

33. Turner JD, Faulkner $H$, Kamgno J, Kennedy MW, Behnke J, Boussinesq M, et al. Allergen-specific lgE and lgG4 are markers of resistance and susceptibility in a human intestinal nematode infection. Microbes Infect. 2005;7:990-6.

34. McSharry C, Xia Y, Holland CV, Kennedy MW. Natural immunity to Ascaris lumbricoides associated with immunoglobulin E antibody to ABA-1 allergen and inflammation indicators in children. Infect Immun. 1999;67:484-9.

35. Perzanowski MS, Ng'ang'a LW, Carter MC, Odhiambo J, Ngari P, Vaughan JW, et al. Atopy, asthma, and antibodies to Ascaris among rural and urban children in Kenya. J Pediatr. 2002;140:582-8.

36. Acevedo N, Sanchez J, Erler A, Mercado D, Briza P, Kennedy M, et al. IgE cross-reactivity between Ascaris and domestic mite allergens: the role of tropomyosin and the nematode polyprotein ABA-1. Allergy. 2009;64:1635-43.

37. Acevedo N, Erler A, Briza P, Puccio F, Ferreira F, Caraballo L. Allergenicity of Ascaris lumbricoides Tropomyosin and lgE Sensitization among Asthmatic Patients in a Tropical Environment. Int Arch Allergy Immunol. 2010;154:195-206.

38. Acevedo N, Mercado D, Vergara C, Sanchez J, Kennedy MW, Jimenez S, et al. Association between total immunoglobulin $E$ and antibody responses to naturally acquired Ascaris lumbricoides infection and polymorphisms of immune system-related LIG4, TNFSF13B and IRS2 genes. Clin Exp Immunol. 2009;157:282-90.

39. Carvalho Kdos A, de Melo-Neto OP, Magalhaes FB, Ponte JC, Felipe FA, dos Santos MC, et al. Blomia tropicalis Blo t 5 and Blo t 21 recombinant allergens might confer higher specificity to serodiagnostic assays than whole mite extract. BMC Immunol. 2013;14:11

40. Arruda LK, Fernandez-Caldas E, Naspitz CK, Montealegre F, Vailes LD, Chapman MD. Identification of Blomia tropicalis allergen Blo $t 5$ by CDNA cloning. Int Arch Allergy Immunol. 1995;107:456-7.

41. Dupont WD, Plummer Jr WD. Power and sample size calculations for studies involving linear regression. Control Clin Trials. 1998;19:589-601.

42. Caraballo $L$. The prevalence of IgE antibodies to ascaris in asthmatic patients living in a tropical environment. J Allergy Clin Immunol. 2007;119:S210.

43. Sharma S, Litonjua AA, Tantisira KG, Fuhlbrigge AL, Szefler SJ, Strunk RC, et al. Clinical predictors and outcomes of consistent bronchodilator response in the childhood asthma management program. J Allergy Clin Immunol. 2008;122:921-8.

44. Knopp S, Mgeni AF, Khamis IS, Steinmann P, Stothard JR, Rollinson D, et al. Diagnosis of soil-transmitted helminths in the era of preventive chemotherapy: effect of multiple stool sampling and use of different diagnostic techniques. PLoS Negl Trop Dis. 2008;2:e331.

45. Marti H, Koella JC. Multiple stool examinations for ova and parasites and rate of false-negative results. J Clin Microbiol. 1993;31:3044-5.

46. Fincham JE, Markus MB, van der Merwe L, Adams VJ, van Stuijvenberg ME, Dhansay MA. Ascaris, co-infection and allergy: the importance of analysis based on immunological variables rather than egg excretion. Trans R Soc Trop Med Hyg. 2007;101:680-2.

47. Neffen H, Fritscher C, Schacht FC, Levy G, Chiarella P, Soriano JB, et al, Asthma control in Latin America: the Asthma Insights and Reality in Latin America (AIRLA) survey. Pan American J Public Health. 2005;17:191-7.

48. Lynch NR, Palenque M, Hagel I, DiPrisco MC. Clinical improvement of asthma after anthelminthic treatment in a tropical situation. Am J Respir Crit Care Med. 1997;156:50-4

49. Stromberg BE. Potentiation of the reaginic ( $\mathrm{gEE}$ ) antibody response to ovalbumin in the guinea pig with a soluble metabolic product from Ascaris suum. J Immunol. 1980;125:833-6. 
50. Schopf L, Luccioli S, Bundoc V, Justice P, Chan CC, Wetzel BJ, et al. Differential modulation of allergic eye disease by chronic and acute ascaris infection. Invest Ophthalmol Vis Sci. 2005;46:2772-80

51. Abou Gamra MM, Tawfeek GM, Abdel Hameed DM. Immunopathogenic role of IgG antibody and RANTES in house dust mite-induced chronic bronchitis. J Egypt Soc Parasitol. 2005;35:107-24.

52. Borish L, Chipps B, Deniz Y, Gujrathi S, Zheng B, Dolan CM, et al. Total serum lgE levels in a large cohort of patients with severe or difficult-to-treat asthma. Ann Allergy Asthma Immunol. 2005;95:247-53.

53. Soto-Quiros M, Avila L, Platts-Mills TA, Hunt JF, Erdman DD, Carper $\mathrm{H}$, et al. High titers of IgE antibody to dust mite allergen and risk for wheezing among asthmatic children infected with rhinovirus. J Allergy Clin Immunol. 2012;129:1499-505.

54. Santos AB, Rocha GM, Oliver C, Ferriani VP, Lima RC, Palma MS, et al. Cross-reactive lgE antibody responses to tropomyosins from Ascaris lumbricoides and cockroach. J Allergy Clin Immunol. 2008;121:1040-6.

55. Maizels RM, Hewitson JP, Smith KA. Susceptibility and immunity to helminth parasites. Curr Opin Immunol. 2012;24:459-66.

56. Ramalingam TR, Pesce JT, Mentink-Kane MM, Madala S, Cheever AW, Comeau MR, et al. Regulation of helminth-induced Th2 responses by thymic stromal lymphopoietin. J Immunol. 2009;182:6452-9.

57. Prefontaine D, Lajoie-Kadoch S, Foley S, Audusseau S, Olivenstein R, Halayko AJ, et al. Increased expression of IL-33 in severe asthma: evidence of expression by airway smooth muscle cells. J Immunol. 2009;183:5094-103.

58. Lechner CJ, Komander K, Hegewald J, Huang X, Gantin RG, Soboslay PT, et al. Cytokine and chemokine responses to helminth and protozoan parasites and to fungus and mite allergens in neonates, children, adults, and the elderly. Immunity \& Ageing. 2013;10:29.

59. Masure D, Vlaminck J, Wang T, Chiers K, Van den Broeck W, Vercruysse J, et al. A role for eosinophils in the intestinal immunity against infective Ascaris suum larvae. PLoS Negl Trop Dis. 2013;7:e2138.

60. Tantisira KG, Colvin R, Tonascia J, Strunk RC, Weiss ST, Fuhlbrigge AL, et al. Airway responsiveness in mild to moderate childhood asthma: sex influences on the natural history. Am J Respir Crit Care Med. 2008;178:325-31.

61. Tantisira KG, Fuhlbrigge AL, Tonascia J, Van Natta M, Zeiger RS, Strunk RC, et al. Bronchodilation and bronchoconstriction: predictors of future lung function in childhood asthma. J Allergy Clin Immunol. 2006;117:1264-71.

\section{Submit your next manuscript to BioMed Central and take full advantage of:}

- Convenient online submission

- Thorough peer review

- No space constraints or color figure charges

- Immediate publication on acceptance

- Inclusion in PubMed, CAS, Scopus and Google Scholar

- Research which is freely available for redistribution

Submit your manuscript at www.biomedcentral.com/submit 